\title{
CONTROL SYSTEM KENDALI KECEPATAN SEPEDA MOTOR LISTRIK DENGAN METODE PID
}

\author{
Yohanes U D Sipul' ${ }^{2}$, Dwi Arman Prasetya ${ }^{1}$, Nachrowie ${ }^{1}$, Wahyu Dirgantara ${ }^{1}$ \\ ${ }_{1}^{1}$ Jurusan Teknik Elektronika UNMER Malang \\ ${ }^{2}$ Departemen Optik dan Hidrolik Lembaga Pengkajian Teknologi TNI-AD \\ Email : Yohanissipoel@gmail.com
}

\begin{abstract}
Abstrak
Dengan meningkatnya jumlah penduduk maka semakin meningkat pula jumlah penggunanaan bahan bakar minyak (BBM). Salah satu jenis kendaraan yang menggunakan BBM adalah sepeda motor, penelitian ini merancang sepeda motor listrik dengan menggunkan motor dc. Permasalahan yang muncul dalam penelitian ini adalah mengendalikan hentakan pada saat menambah kecepatan sepeda motor sehinngga pengendara aman serta nyaman dalam menggunakan kendaraannya. Dengan menggunakan metode PID diharapkan hentakan yang diakibatkan dari penambahan kecepatan dapat dihilangkan.
\end{abstract}

Kata Kunci: Motor DC, Metode PID

\section{Pendahuluan}

Kendaraan roda dua merupakan kendaraan yang mepunyai gas buang yang menyebabkan polusi udara. Berkembangnya otomotif membuat penggunaan bahan bakar minyak semakin dicari[1], jika harga bahan bakar minyak bumi terus meningkat banyak dari para pengelola industri otomotif beralih dengan mengembangkan kendaran seperti sepeda motor dengan memanfaatkan listrik.

Penelitian dari [2] Kontrol PID merupkan controller yang sampai hari ini banyak digunakan di dunia industry. Banyak hal yang bisa dilakukan dengan kontrol PID salah satunya adalah menentukan parameter atau tuning.

Penelitian dari (Vinventius N.F, 2014) menjelaskan sama seperti paragraph diatas, dimana keunggulan dari kontrol Proporsional Integral Deferensial (PID) adalah stabilitas yang baik dengan tingkat error dan overshoot yang kecil. Implmentasi kontrol ini diaplikasikan pada alat screw conveyot yang dirancang dengan menggunakan motor direct current (DC) yang dikontrol dengan mikrokontroller ATMega8535[3][4]. Keluaran dari mikrokontroller berupa PWM menjadi yang diubah menjadi masukan untuk penggerak driver motor yang mana kecepatan keluaran dari motor akan dideteksi oleh sensor rotary encoder.

Dari penelitian diatas maka dalam penelitian ini adalah membuat dan mengimplementasikan motor DC sebagai sepeda motor listrik yang mempunyai kecepatan setara dengan seperda motor bahan bakar minyak dengan menggunakan kontrol PID[5].

\section{Metode penelitian}

Metode yang digunakan dalam penelitian ini adalah dengan kontrol PID, metede ini di implementasikan guna menyelesaikan pengontrolan PWM dengan masukan dari beberapa sensor. Adapun variable yang digunakan dalam penelitian ini antara lain:

1. Motor DC

2. Sensor Hall

3. Potensio (Gas)

Metode perancangan keseluruhan alat digambarkan dalam bentuk diagram alir perancangan dan pembuatan algoritma pemrogaman system kontrol pada kendaraan seperti pada berikut ini[6][7][8]. 


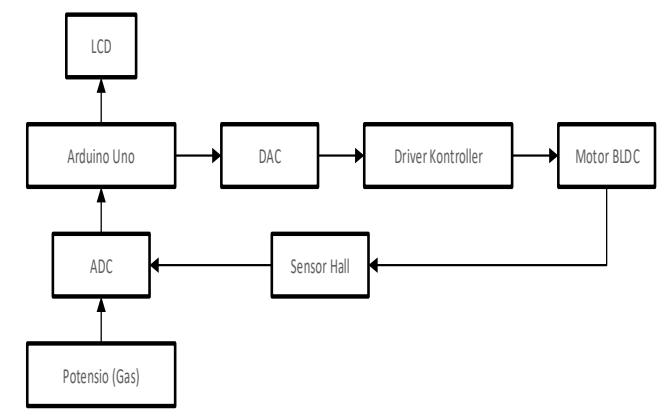

Gambar 2.1 Blog diagram sistem

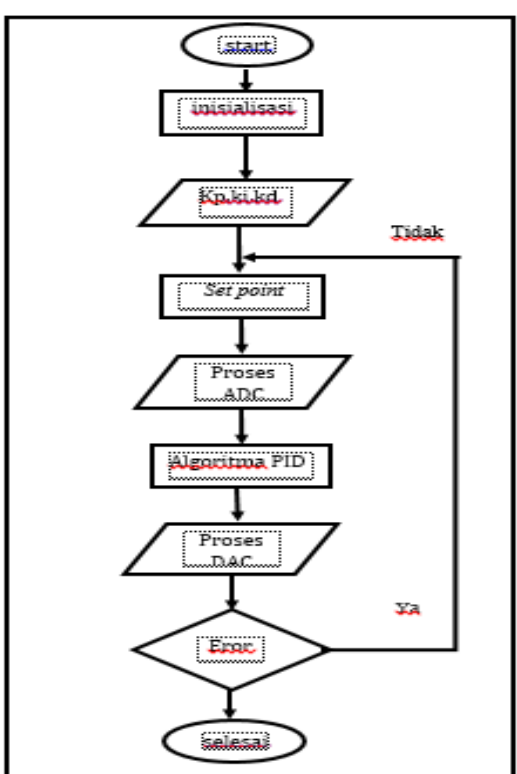

Gambar 2.2 Flow chart sistem

\section{Hasil dan Analisis}

Pengujian dilakukan untuk mengetahuihasil rancangan dari sistem yang dibuat. Pengujian yang dilakukan ada dua tahapan penting antara lain pengujian perangkat keras dan perangkat lunak.

\subsection{Pengujian Perangkat Keras}

1. Pengujian sumber tegangan

Bertujuan untuk mengetahui apakah catu daya dari sumber sudah sesuai dengan kriteria motor listrik yang dipakai.

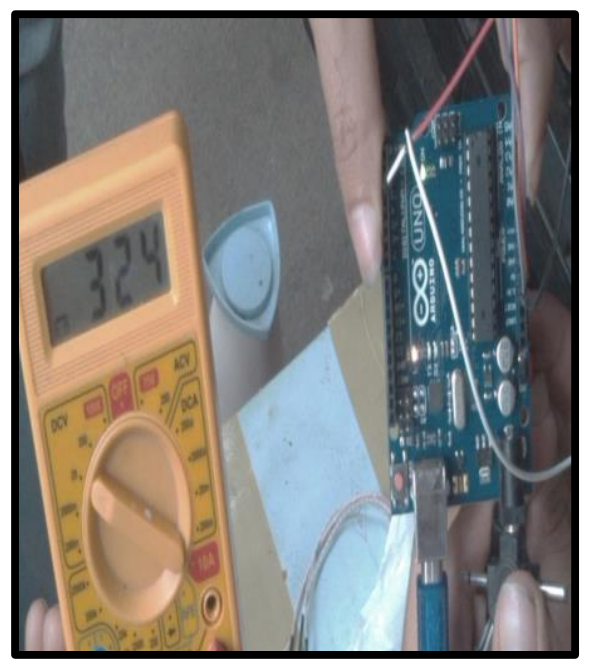

Gambar 3.1 Pengujian tegangan sumber minimum

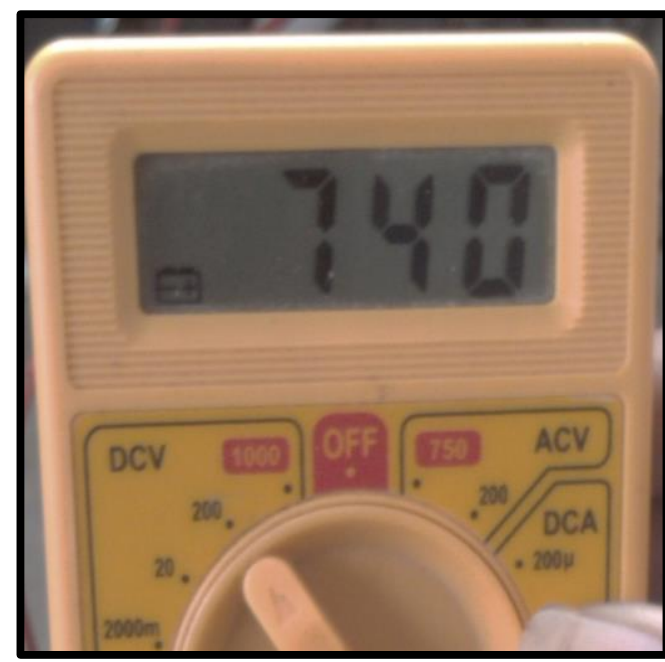

Gambar 3.2 Pengujian tegangan sumber motor BLDC

2. Pengujian Arduino Uno

Bertujuan untuk mengetahui performa dari mikrokontroller yang digunakan dalam hal ini adalah tipe Arduino uno[9].

Control System Kendali Kecepatan Sepeda Motor Listrik Dengan Metode Pid (Yohanes U D 


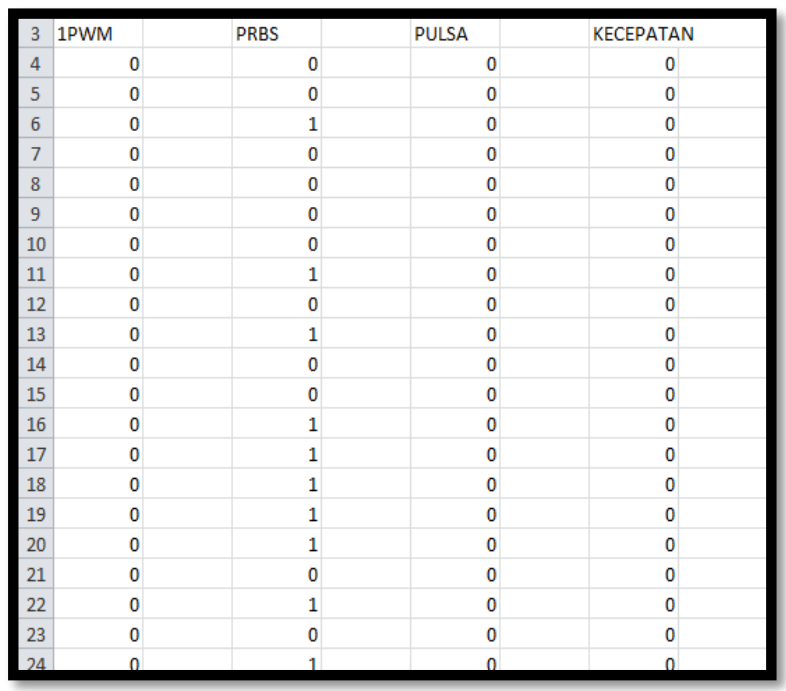

Gambar 3.2. Hasil pengiriman data dari minimum ke sistem laptop

3. Pengujian Driver Motor

Hal ini dilakukan untuk mengetahui mengukur PWM dan tegangan yang akan digunakan oleh motor DC sehingga tidak menimbulkan error[10][11][12].

Tabel 3.1. Hasil Pengukuran PWM dan

\begin{tabular}{|c|c|c|}
\multicolumn{3}{|c|}{ Tegangan } \\
\hline No. & $\begin{array}{c}\text { PWM } \\
\left(\mathrm{ms}^{-1}\right)\end{array}$ & $\begin{array}{c}\text { TEGANGAN } \\
(\mathrm{V})\end{array}$ \\
\hline 11 & 0 & $\mathbf{0}$ \\
\hline 2 & 10 & $\mathbf{1 2 . 8}$ \\
\hline 3 & 20 & $\mathbf{1 2 . 8}$ \\
\hline 4 & 30 & $\mathbf{1 2 . 9}$ \\
\hline 5 & 40 & $\mathbf{1 2 . 9}$ \\
\hline 6 & 50 & $\mathbf{1 2 . 9}$ \\
\hline 7 & 60 & $\mathbf{1 5 . 1}$ \\
\hline 8 & 70 & $\mathbf{1 5 . 1}$ \\
\hline 9 & 80 & $\mathbf{1 5 . 1}$ \\
\hline 10 & 90 & $\mathbf{1 5 . 1}$ \\
\hline 11 & 100 & $\mathbf{1 5 . 2}$ \\
\hline 12 & 110 & $\mathbf{1 5 . 3}$ \\
\hline 13 & 120 & $\mathbf{1 5 . 4}$ \\
\hline 14 & 130 & $\mathbf{1 6 . 1}$ \\
\hline 15 & 140 & $\mathbf{1 6 . 2}$ \\
\hline
\end{tabular}

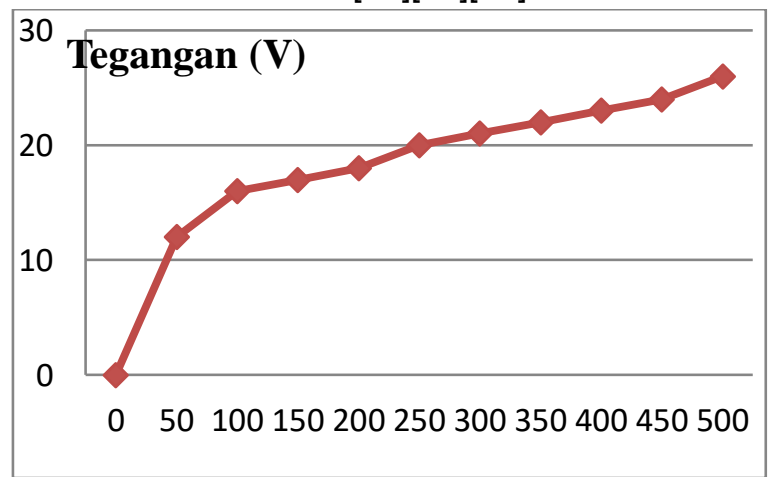

Gambar 3.3. Grafik Hubungan PWM dan Vout Driver Motor Listrik 
Tabel 3.2. Hasil pengukuran hubungan PWM dan RPM driver motor listrik

\begin{tabular}{|c|c|c|}
\hline No. & $\begin{array}{c}\text { PWM } \\
\left(\mathrm{ms}^{-1}\right)\end{array}$ & $\begin{array}{c}\text { RPM } \\
(\mathrm{m} / \mathrm{s})\end{array}$ \\
\hline 1 & 0 & 0 \\
\hline 2 & 10 & 900 \\
\hline 3 & 20 & 960 \\
\hline 4 & 30 & 1500 \\
\hline 5 & 40 & 2040 \\
\hline 6 & 50 & 2160 \\
\hline 7 & 60 & 2820 \\
\hline 8 & 70 & 3840 \\
\hline 9 & 80 & 5760 \\
\hline 10 & 90 & 6360 \\
\hline 11 & 100 & 7380 \\
\hline 12 & 110 & 8880 \\
\hline 13 & 120 & 9420 \\
\hline 14 & 130 & 1030 \\
\hline 15 & 140 & 11020 \\
\hline \multicolumn{3}{|c}{} \\
\hline
\end{tabular}

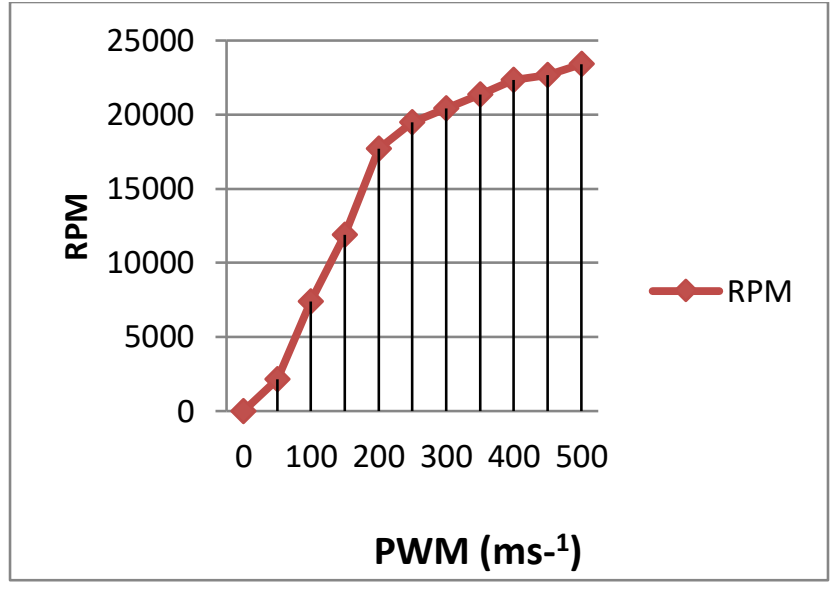

Gambar 3.4. Grafik Hubungan RPM dan PWM

\subsection{Pengujian Perangkat Lunak}

Pada bagian ini menunjukkan hasil simulasi RPM dan tegangan tanpa menggunakan PID dan yang menggunakan kontrol PID, seperti terlihat pada Gambar 7 dan Gambar 8.

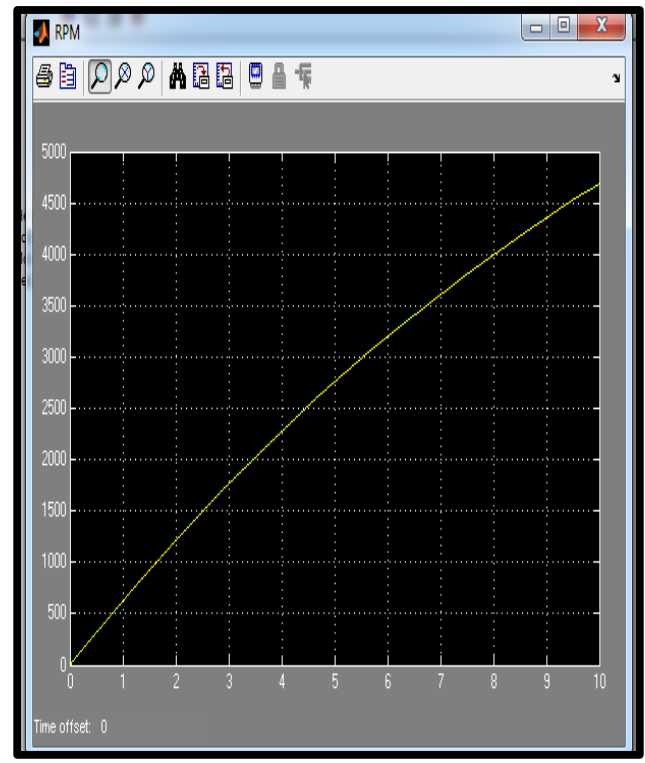

Gambar 3.5. Simulasi RPM dan Tegangan tanpa PID

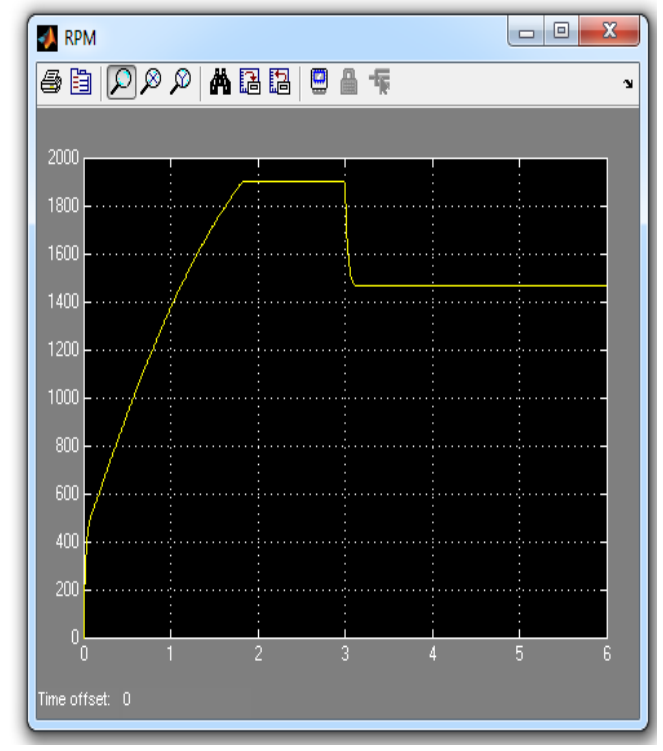

Gambar 3.6. Simulasi RPM dan Tegangan menggunakan PID

\section{Kesimpulan}

Berdasarkan hasil perancangan sistem, analisis dan pengujian didapatkan kesimpulan, antara lain:

1. Penggunaan pengontrolan PID pada motor listrik akan menjaga kestabilan kecepatan motor listrik, dibandingkan tanpa menggunakan PID, yang akan mengakibatkan putaran motor listrik tidak stabil. 
2. Proses kendali dengan sistem penelaan parameter kendali PID yang berfungsi untuk mengatur putaran motor BLDC.

3. Pengujian perubahan set point pada motor BLDC dilakukan dengan mensimulasi menggunakan matlab Simulink.

4. Kapasitas beban pada sepeda motor listrik mempengaruhi laju dari sepeda motor tersebut.

5. Pada saat start awal jumlah ampere yang dibutuhkan motor untuk menggerakkan roda $18 \mathrm{~A}$ $-20 \mathrm{~A}$.

\section{References}

[1] M. Octavian, Ari; Darmawan, Hofman; Nurohmah, Hidayatul; Ali, "Optimasi Dual Axis Tracking Untuk Photovoltaic Berbasis Firefly Algorithm dan Ant Colony Optimization," SinarFe7, 2018.

[2] Handy Wicaksono and Josaphat Pramudijanto, "Kontrol PID Untuk Pengaturan Kecepatan Motor DC Dengan Metode Tuning Direct Synthesis," J. Tek. Elektro, 2004.

[3] R. Bimarta, A. E. Putra, and A. Dharmawan, "Balancing Robot Menggunakan Metode Kendali Proporsional Integral Derivatif," IJEIS (Indonesian J. Electron. Instrum. Syst., 2015.

[4] I. Mujahidin, S. H. Pramono, and A. Muslim, "5.5 Ghz Directional Antenna with 90 Degree Phase Difference Output," 2019.

[5] L. M. Argentim, W. C. Rezende, P. E. Santos, and R. A. Aguiar, "PID, LQR and LQR-PID on a quadcopter platform," in 2013 International Conference on Informatics, Electronics and Vision, ICIEV 2013, 2013.

[6] M. A. R. Arif Rahman Hakim, Sumardi, "Kontrol Posisi Pada Sistem Pergerakan Mobile Robot Kinematic," Article, 2015.

[7] I. Mujahidin, "Directional $1900 \mathrm{Mhz}$ Square Patch Ring Slot Microstrip Antenna For WCDMA," JEEMECS (Journal Electr. Eng. Mechatron. Comput. Sci., 2019.

[8] M. Ali, "Kontrol Kecepatan Motor DC Menggunakan PID Kontroler Yang Ditunning Dengan Firefly Algorithm," Intake J. Penelit. IImu Tek. Dan Terap., 2012.

[9] L. Petru and G. Mazen, "PWM control of a DC motor used to drive a conveyor belt," in Procedia Engineering, 2015.

[10] J. T. Elektro, F. T. Industri, and U. K. Petra, "Kontrol PID Untuk Pengaturan Kecepatan Motor DC Dengan Metode Tuning Direct Synthesis," vol. 4, no. 1, pp. 10-17, 2004.

[11] X. Zhang, X. Li, and K. Lu, "Research on an intelligent solar tracking system based on LPC2131," in Proceedings - 2012 3rd IEEE International Conference on Network Infrastructure and Digital Content, IC-NIDC 2012, 2012.

[12] T. Takagi and M. Sugeno, "Fuzzy Identification of Systems and Its Applications to Modeling and Control," IEEE Trans. Syst. Man Cybern., 1985.

\section{Daftar Riwayat Hidup}

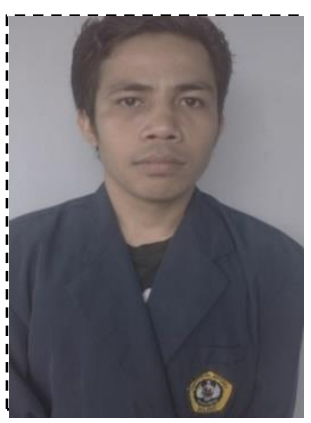

Nama

NIM

Tempat Tanggal Lahir

Agama

Alamat

Jurusan

Nomor Hp

Email
Yohanes Umbu Deki Sipul

11450013

Katiku Loku 12 April 1989

Kristen Katolik

Desa Mata Woga,Kec.Katiku Tana-Sumba-NTT

Teknik Elektro

081249597568

: Yohanissipoel@gmail.com 